\title{
OPTIMIZING OF COMPETITIVE ADSORPTION METHYLENE BLUE AND METHYL ORANGE USING NATURAL ZEOLITE FROM ENDE-FLORES
}

\author{
$\underline{\text { Jumilah Gago' }}$ and Yulius Dala Ngapa ${ }^{*}$ \\ ${ }^{1}$ Biology Education, Faculty of Education and Teacher Training, Flores University \\ Jl. Sam Ratulangi Ende, Flores - NTT 86318, Indonesia \\ ${ }^{2}$ Physics Education, Faculty of Education and Teacher Training, Flores University \\ Jl. Sam Ratulangi Ende, Flores - NTT 86318, Indonesia \\ * Correspondence: Tel. 082260078253, e-mail: ydalangapa@gmail.com
}

\begin{abstract}
Waste from the textile industry is considered a potential source of environmental pollution, especially water, because it contains dangerous dyes. In this research, natural zeolite is an effective and efficient alternative to overcome pollution caused by methylene blue and methyl orange dyes. Activation of natural zeolite was carried out with $3 \mathrm{M} \mathrm{HCl}$ solution and was characterized using X-Ray Diffraction (XRD) and Scanning Electron Microscope (SEM). Simultaneously, the methylene blue and methyl orange adsorption processes were studied in variations in the weight of the adsorbent, contact time, and $\mathrm{pH}$. The concentration of dyes left in the solution was observed with UV-Vis Spectrophotometer. The results showed that the adsorption capacity of natural zeolite in absorbing methylene blue was $21.189 \mathrm{mg} / \mathrm{g}$ and methyl orange was $18.208 \mathrm{mg} / \mathrm{g}$. The optimum conditions of dyes adsorption are achieved with successive adsorbent weights $0.3 \mathrm{~g}$ and $0,4 \mathrm{~g}$, following contact times 60 minutes and 90 minutes, and successive $\mathrm{pH} 6$ and 2 . The adsorbent weight factor, contact time, and $\mathrm{pH}$ affect the adsorption of dyes by natural zeolite from Ende.
\end{abstract}

Keywords: natural zeolite, activation, adsorption, methylene blue, methyl orange

\section{INTRODUCTION}

One of the leading industries being developed in Indonesia is the textile and garment industry. This industry has been able to reduce unemployment in Indonesia because it is a labour-intensive industry that absorbs many workers. Also, the textile industry plays a role as a contributor to foreign exchange [1]. However, the advancement of the textile industry can harm the environment if it is not balanced with the treatment of dye waste during the production process.

Liquid dye waste from the textile industry will make a significant contribution to environmental pollution [2].

The use of synthetic dyes in this industry is an alternative strategy because it is more stable than natural dyes, is easy to obtain, and is relatively inexpensive [3]. Organic dyes such as methylene blue and methyl orange are the most widely used 
dyes. The absorption ability of the fabric to dye is around $80-85 \%$, and the rest will be lost in the washing process. Synthetic dye waste released into water will be a great danger to humans and the environment because of its carcinogenicity and even toxicity and is difficult to degrade by microorganisms [4].

Several methods have been developed during the last few years to control and remove dye waste present in waters, such as ultrafiltration, coagulation, biological treatment, electrochemical, and adsorption [5-8]. Among the developed methods, adsorption was chosen as the most potential method because of its easy operation, high efficiency and low cost, and it does not cause harmful side effects [9].

Adsorption is the process of absorption of a molecule (adsorbate) on the surface of another substance (adsorbent) due to the attractive force between the two substances [10]. The adsorbent innovation being developed is a natural mineral resource with high absorption capacity, is easily available at low cost, and has abundant availability. These criteria exist for natural zeolite [11].

Zeolite is an aluminosilicate mineral in the form of tetrahedral $\mathrm{TO}_{4}(\mathrm{~T}=\mathrm{Al}, \mathrm{Si})$, which is hydrated in alkaline and alkaline earth metals [12]. Natural zeolites scattered in Ende district - NTT are around 20 million tonnes. This large enough reserve can be maximally utilized for environmental purposes [13].

Utilization of natural zeolite Ende as a waste adsorbent in liquid has been carried out, and the results show that the quality of natural zeolite Ende as adsorbent is not different from the zeolite commonly used in research originating from the Bayah and Cikalong areas [14]. Anion dye adsorption study (methyl orange) using zeolite $\mathrm{NaA} /$ $\mathrm{CuO}$ showed that the adsorption efficiency of zeolite against waste reached $98 \%$ [15].

To further optimize the utilization of natural zeolite in Ende, an in-depth study of its potential and characterization as an adsorbent is needed. Natural zeolite has a large $\mathrm{Si} / \mathrm{Al}$ ratio but still contains impurities in the form of metal oxides so that the surface area is low. An activation treatment is needed in order to increase its adsorption ability.

Based on the above background, it is necessary to research to obtain data on the characterization of natural zeolites in Ende. Besides, Ende's natural zeolite adsorption ability needs to be known not only for cation dyes (methylene blue) but also for its adsorption ability against anion dyes (methyl orange). This research is also an effort to overcome pollution caused by textile dye waste.

\section{METHODS}

\section{Materials}

The materials used in this research were the natural zeolite from Ende - Flores, $\mathrm{HCl}$ p.a, $\mathrm{HCl}$ p.a Merck 38\%, aquades, universal $\mathrm{pH}$ indicator, methylene blue Merck 115943, dan methyl orange C. I. 13025.

\section{Instrumentation}

The instruments used in this study were the Kokusan $\mathrm{H}-107$ centrifuge, Titramax 101 shaker, Shimadzu AA-7000 SSA (Atomic Absorption Spectrophotometer), Shimadzu 1700 UV-Vis spectrophotometer, Scanning Electron Microscope (SEM) Carl-Zeiss 
Bruker EVO MA10, X-Ray Diffraction (XRD) Bruker D4, analytical balances, furnaces, ovens and glassware.

\section{Procedure}

\section{a. Preparation of Sample Natural Zeolite}

Natural zeolite samples were resized into a fine powder with grain sizes passing a 200 mesh grain size, the $\mathrm{pH}$ neutralized with distilled water, then heated in an oven at 105 ${ }^{\circ} \mathrm{C}$ for 3 hours, and stored in a desiccator for further use.

\section{b. Activation of Natural Zeolite}

Natural zeolite samples are chemically activated. Chemical activation was carried out by mixing 50 grams of zeolite in $\mathrm{HCl} 3.0$ $M$. The mixture was stirred with a magnetic stirrer for 3 hours, then rinsed with aquades until the $\mathrm{pH}$ was neutral and dried in a furnace at $300{ }^{\circ} \mathrm{C}$ for 3 hours.

\section{c. Characterization of Natural Zeolit}

Natural zeolite characterization was analyzed using X-Ray Diffraction (XRD) instrument, and the surface morphology of natural zeolite was analyzed by instrument Scanning Electron Microscope (SEM).

\section{d. Preparation of Standard Solution Methylene Blue and Methyl Orange $1000 \mathrm{mg} / \mathrm{L}$}

$0.5 \mathrm{~g}$ of methylene blue powder and $0.5 \mathrm{~g}$ of methyl orange were put into a $500 \mathrm{ml}$ measuring flask and diluted to the limit mark.

\section{e. Determination of Wavelength for Absorption of Methylene Blue and Methyl Orange}

The determination of wavelength is done by measuring the absorbance of standard solutions in the range of $650-700$ $\mathrm{nm}$ for the wavelength of methylene blue and
$300-600 \mathrm{~nm}$ for the wavelength of methyl orange.

\section{f. Preparation of Standard Curves for Methylene Blue and Methyl Orange}

Standard series solution of methylene blue and methyl orange with a concentration of $1 ; 2 ; 3 ; 4 ; 5$; and $6 \mathrm{mg} / \mathrm{L}$ made from the liquor through a dilution process. The absorbance was measured at the maximum wavelength.

\section{g. Determination of the Optimum Weight}

Adsorbent of zeolite with a weight variation of $0.1 ; 0.2 ; 0.3 ; 0.4 ; 0.5 ; 0.6 \mathrm{~g}$ is added in $20 \mathrm{~mL}$ of dyes with a concentration of $400 \mathrm{mg} / \mathrm{L}$, the solution is shaken for 1 hour . The solution was centrifuged for 15 minutes at a speed of $5000 \mathrm{rpm}$. The absorbance of the dyes was determined using a UV-Vis spectrophotometer.

\section{h. Determination of the Optimal Contact Time}

The optimum weight obtained was added in $20 \mathrm{~mL}$ of methylene blue and methyl orange with a $400 \mathrm{mg}$ / L concentration, then shaken with time variations of $30,60,90,120$, 150 minutes. The solution was centrifuged for 15 minutes at a speed of $5000 \mathrm{rpm}$. The absorbance of the dyes was determined using a UV-Vis spectrophotometer.

\section{i. Determination of $\mathrm{pH}$ Optimum}

The optimum weight obtained was added in $20 \mathrm{~mL}$ of methylene blue and methyl orange with a $400 \mathrm{mg}$ / L concentration, then shaken at the optimum time. The solution was centrifuged for 15 minutes at a speed of $5000 \mathrm{rpm}$. The absorbance of the dyes was determined using a UV-Vis spectrophotometer. 


\section{j. Determination of Adsorption Isotherms}

The optimum weight obtained was added in $20 \mathrm{~mL}$ of methylene blue and methyl orange with various concentrations of 100 , $200,400,600,800,1000 \mathrm{mg} / \mathrm{L}$, then shaken at the time, and the optimum $\mathrm{pH}$ was obtained. The solution was centrifuged for 15 minutes at a speed of $5000 \mathrm{rpm}$. The absorbance of the solution was measured using a UV-Vis spectrophotometer at the maximum wavelength obtained.

The adsorption capacity can be determined using the formula:

$$
\mathrm{qe}=\frac{\mathrm{v}\left(\mathrm{C}_{\mathrm{o}}-\mathrm{C}_{\mathrm{e}}\right)}{\mathrm{m}}
$$

Where:

$$
\begin{aligned}
& \text { qe }=\text { adsorption capacity }(\mathrm{mg} / \mathrm{g}) \\
& \mathrm{V}=\text { volume of solution }(\mathrm{L}) \\
& \mathrm{C}_{\circ}=\text { initial dye concentration }(\mathrm{mg} / \mathrm{L}) \\
& \mathrm{C}_{\mathrm{e}}=\text { finish dye concentration }(\mathrm{mg} / \mathrm{L}) \\
& \mathrm{m}=\text { mass of zeolite }(\mathrm{gram})
\end{aligned}
$$

\section{RESULTS AND DISCUSSION}

\section{Preparation of Sample Natural Zeolite}

The initial preparation is done by refining the zeolite to produce a fine powder measuring 150 mesh. This process aims to uniform the granules and enlarge the surface to optimise the zeolite's adsorption capacity. Washing and heating are carried out in the preparation stage to remove impurities and evaporate the water present to increase the pore size [16].

\section{Activation of Natural Zeolite}

Natural zeolite still contains water vapour and metal oxides, causing low adsorption and ion exchange capabilities.
The quality of natural zeolites can be improved through the activation process. This process aims to remove absorbed metal oxides and cover the zeolite surface so that the contact area becomes the largest. The addition of the contact area can increase the ability of zeolite as an adsorbent [17].

\section{Characterization of Natural Zeolite}

$\mathrm{XRD}$ is a qualitative and quantitative analysis method that functions to analyze the structure of zeolite powder. When analyzed by $\mathrm{XRD}$, all materials containing certain crystals will produce distinctive peaks. The diffractogram of the results of natural zeolite analysis is shown in Figure 1

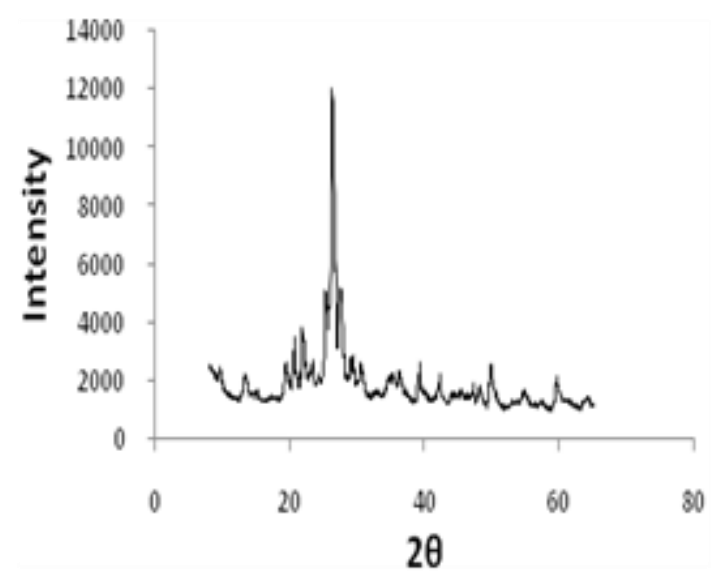

Fig 1. Diffractogram of Natural Zeolite

XRD analysis showed that the natural zeolite of Ende was a mixture of clinoptilolite and mordenite. The characteristic peaks evidence this in the JCPDS (Joint Committee on Powder Diffraction Standard) data with high intensity appearing at $25.60^{\circ}, 26.25^{\circ}$, and $27.67^{\circ}$ for mordenite and clinoptilolite intensity appearing at angles of $9.74^{\circ}, 13.38^{\circ}$. And $29.07^{\circ}$. The peaks with the highest intensity are owned by mordenite, and this indicates that mordenite is a type of natural 
zeolite with a large abundance scattered in Ende.

The morphology of the crystal particles was observed by SEM (Scanning Electron Microscope) at a magnification of 3000 times. Figure 2 shows the surface morphology of the natural zeolite in Ende. The material shows the natural zeolite indicator based on SEM observations in the form of flat sheets shaped like bars with stacked and random arrangements [18].

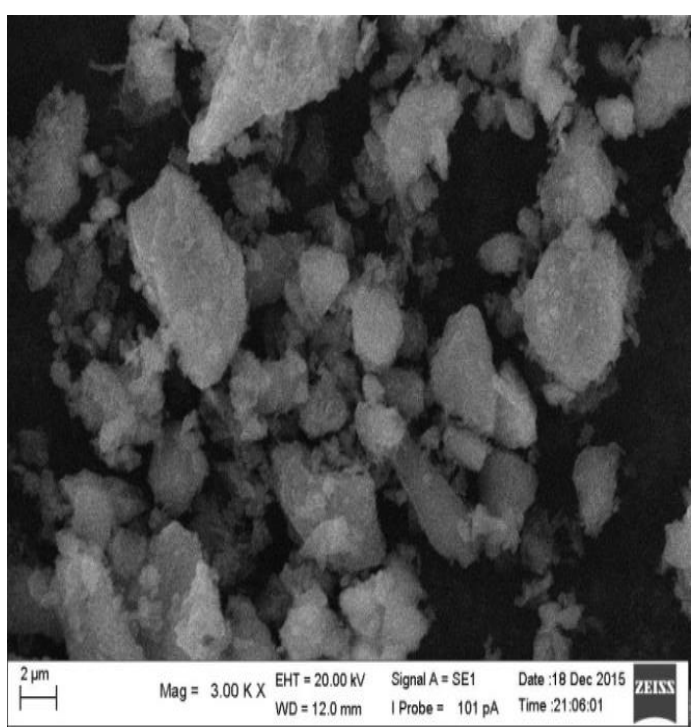

Fig 2. Surface morphology of natural zeolite

\section{Determination of the Maximum Wave- length for Dyes Absorption}

The concentrations of dyes can be qualitatively compared from the intensity of the color that will fade when the adsorption process ends. Quantitatively, the determination is measured by a UV-Vis spectrophotometer in the wavelength range of $600-700 \mathrm{~nm}$ for methylene blue and 400 $550 \mathrm{~nm}$ for methyl orange. The maximum wavelengths of methylene blue and methyl orange were obtained at $664 \mathrm{~nm}$ and $463 \mathrm{~nm}$.

\section{Determination of the Optimum Weight}

The adsorbent weight used ranges from 0.1 to $0.6 \mathrm{~g}$. The effect of adsorbent weight on the adsorption capacity of zeolite on methylene blue and methyl orange is shown in Table 1.

Table 1 Adsorption capacity of natural zeolite against methylene blue (MB) and methyl orange (MO) at various adsorbent weight

\begin{tabular}{ccc}
\hline $\begin{array}{c}\text { Adsorbent } \\
\text { Weight }\end{array}$ & \multicolumn{2}{c}{$\begin{array}{c}\text { Adsorption Capacity } \\
\text { (mg/g) }\end{array}$} \\
\cline { 2 - 3 }$(\mathrm{g})$ & $\mathrm{MB}$ & $\mathrm{MO}$ \\
\hline 0.1 & 4.817 & 3.935 \\
0.2 & 6.913 & 4.093 \\
0.3 & 12.454 & 7,178 \\
0.4 & 11.761 & 10.514 \\
0.5 & 9.483 & 9.205 \\
0.6 & 8.013 & 8.184 \\
\hline
\end{tabular}

Based on Table 1, the optimum adsorbent weight for methylene blue uptake is $0.3 \mathrm{~g}$. The optimum adsorbent weight for methyl orange uptake is $0.4 \mathrm{~g}$. The optimum point occurs because the more adsorbent is used, the more surface area (active site of the zeolite) is, so the greater the possibility of adsorption. However, after the optimum weight, there is a decrease in the dye content that is absorbed. This decrease is because not all active sites are filled with an adsorbate. Large numbers of active sites take longer to reach an equilibrium state [19].

The highest adsorption capacity is obtained when all active sites of the adsorbent have been filled with an adsorbate. In the methylene blue and methyl orange adsorption process, the highest adsorption capacity was obtained with a small adsorbent weight. The adsorbent weight can increase the active side, thus allowing the active side 
to not interact with the adsorbate and cause a decrease in adsorption capacity [20]. Therefore, in the results of this study, the sample with high adsorbent weight did not produce a high adsorption capacity.

\section{Determination of the Optimal Contact Time}

Determining the optimum contact time aims to determine the time required to achieve the adsorption equilibrium of methylene blue and methyl orange by natural zeolite adsorbent. Generally, the longer the contact time between the adsorbent and the adsorbate, the more adsorbed the adsorbate will be. The zeolite adsorbent in adsorbing methylene blue and methyl orange increased respectively at 60 minutes and 90 minutes (optimum contact time), then decreased slightly in the next minute. Adsorbate so that the addition of adsorption time will only have a slight increase in the adsorption capacity or tend to be constant [21]. The effect of contact time on the adsorption capacity of natural zeolites on methylene blue and methyl orange is presented in Table 2.

Table 2 Adsorption capacity of natural zeolite against the dyes at various contact times

\begin{tabular}{ccc}
\hline \multirow{2}{*}{$\begin{array}{c}\text { Contact } \\
\text { Time } \\
\text { (minute) }\end{array}$} & \multicolumn{2}{c}{$\begin{array}{c}\text { Adsorption Capacity } \\
(\mathrm{mg} / \mathrm{g})\end{array}$} \\
\cline { 2 - 3 } & $\mathrm{MB}$ & $\mathrm{MO}$ \\
\hline 30 & 11.825 & 9.467 \\
60 & 12.978 & 9.713 \\
90 & 11.891 & 10.815 \\
120 & 11.675 & 10.014 \\
150 & 11.228 & 9.624 \\
\hline
\end{tabular}

In determining the optimum contact time, it is necessary to know that the longer the adsorption time, the electrical stability will be disturbed. The adsorption capacity after the optimum contact time tends to decrease [22].

\section{Determination of Optimum pH}

One of the important parameters that determine the uptake of dyes by natural zeolite is the degree of acidity $(\mathrm{pH})$. Changes in $\mathrm{pH}$ can affect the chemical and surface properties of the adsorbent, the solubility of the adsorbate, and ion competition in the absorption process [23]. The absorption of natural zeolite to methylene blue increased at $\mathrm{pH}=6,13.298 \mathrm{mg} / \mathrm{g}$. The increase in the adsorption capacity of methyl orange occurred at $\mathrm{pH}=2$ (optimum $\mathrm{pH}$ ) of 11.427 $\mathrm{mg} / \mathrm{g}$. This indicates that the dye adsorption process is influenced by electrostatic interactions or ion exchange with $\mathrm{H}+$ ions on the active site of the zeolite. The decrease in adsorption capacity at higher $\mathrm{pH}$ is due to the condition that the active site of the zeolite is saturated [24]. The adsorption and absorption capacities of dyes at various $\mathrm{pH}$ are shown in Table 3.

Tabel 3 Adsorption capacity of natural zeolite against the dyes at various $\mathrm{pH}$

\begin{tabular}{ccc}
\hline \multirow{2}{*}{$\mathrm{pH}$} & \multicolumn{2}{c}{ Adsorption Capacity (mg/g) } \\
\cline { 2 - 3 } & $\mathrm{MB}$ & $\mathrm{MO}$ \\
\hline 2 & 11.407 & 11.427 \\
4 & 12.823 & 10.325 \\
6 & 13.298 & 10.011 \\
8 & 13.014 & 9.763 \\
10 & 12.115 & 8.728 \\
\hline
\end{tabular}

The bond between zeolite adsorbent and dye adsorbate in this study is the Van der Waals bond. Van der Waals bonds are 
defined as the attractions between molecules due to dipole-dipole attractions. Dipolar molecules combine with neighbouring molecules until the negative pole of one molecule approaches the positive pole of another molecule. Natural zeolites contain a certain amount of negative charge and positive charge. Adsorbate, which has a negative charge, will bind to the positive charge of natural zeolite, while adsorbate, which has a positive charge, will bind to the negative charge of natural zeolite.

\section{Determination of Adsorption Isotherms}

The relationship between the adsorbate concentration and the absorption rate on the adsorbent surface can be determined through the adsorption isotherm. The results obtained indicate that the increase in the initial concentration of dyes is followed by an increase in the amount of these substances adsorbed (adsorption capacity). Table 4 shows the adsorption capacity of natural zeolite at various initial adsorbate concentrations.

Table 4 Adsorption capacity of natural zeolite against the dyes at various initial concentrations

\begin{tabular}{ccc}
\hline \multirow{2}{*}{$\begin{array}{c}\text { Concentration } \\
\text { adsorbate } \\
(\mathrm{mg} / \mathrm{L})\end{array}$} & \multicolumn{2}{c}{$\begin{array}{c}\text { Adsorption Capacity } \\
(\mathrm{mg} / \mathrm{g})\end{array}$} \\
\cline { 2 - 3 } & $\mathrm{MB}$ & $\mathrm{MO}$ \\
\hline 100 & 8.655 & 6.409 \\
200 & 11.751 & 8.132 \\
400 & 14.218 & 11.427 \\
600 & 16.013 & 14.503 \\
800 & 21.017 & 17.113 \\
1000 & 21.189 & 18.208 \\
\hline
\end{tabular}

The adsorption capacity of natural zeolite to adsorbed dyes increased the initial concentration of the adsorbate. Because the higher the adsorbate concentration, the more the number of dyes in the adsorbed solution.

The nature of the zeolite influences the zeolite's ability to absorb an adsorbate. Zeolite with chemical activation provides quality values that meet the standards. Impurities such as water vapour and other minerals that can interfere with the absorption process tend to be less so that the zeolite can adsorb more the dyes molecules. The excellent quality of natural zeolite is proven by testing methylene blue and methyl orange adsorption, which results in large adsorption capacity values [25]. The adsorption capacity of dyes reached the highest values, namely $21.189 \mathrm{mg} / \mathrm{g}$ and $18.208 \mathrm{mg} / \mathrm{g}$, respectively.

The determination of the adsorption isotherm of dyes by natural zeolites was analyzed using two adsorption isotherm models, namely Langmuir and Freundlich models. The Langmuir isotherm is based on the adsorption of the monolayer on the homogeneous active site of the adsorbent, while the Freundlich isotherm describes the adsorption on heterogeneous surfaces. The linear form of the Freundlich equation is expressed in the equation:

$$
\log \mathrm{q}_{\mathrm{e}}=\log \mathrm{K}_{\mathrm{f}}+\frac{1}{\mathrm{n}} \log \mathrm{C}_{\mathrm{e}}
$$

Where: $\mathrm{Ce}=$ the adsorbate equilibrium concentration $(\mathrm{mg} / \mathrm{L})$, qe $=$ the adsorption capacity at equilibrium $(\mathrm{mg} / \mathrm{g}), \mathrm{Kf}$ and $\mathrm{n}=$ the constants and the adsorption intensity. The linear form of the Langmuir isotherm equation is:

$$
\frac{\mathrm{C}_{\mathrm{e}}}{\mathrm{q}_{\mathrm{e}}}=\frac{\mathrm{C}_{\mathrm{e}}}{\mathrm{Q}}+\frac{1}{\mathrm{Qb}}
$$

$\mathrm{Q}=$ the maximum adsorption on the monolayer $(\mathrm{mg} / \mathrm{g})$ and $\mathrm{b}=$ the Langmuir 
constant, which is related to the binding $(\mathrm{mL} / \mathrm{mg})$ affinity. Also, $\mathrm{b}=\mathrm{a}$ measure of the adsorption energy [26].

In the adsorption of methylene blue and methyl orange with natural zeolites, the Langmuir isotherm correlation value is greater than that of Freundlich. This shows that the adsorption process that occurs is monolayer (homogeneous) adsorption. Isotherm parameter values $\mathrm{qm}, \mathrm{Kf}, \mathrm{n}$, and $\mathrm{R}^{2}$ are presented in Table 5.

Tabel 5 Natural zeolite adsorption isotherm parameters for methylene blue and methyl orange

\begin{tabular}{|c|c|c|c|}
\hline \multicolumn{2}{|c|}{ Parameters } & $\mathrm{MB}$ & MO \\
\hline & $\mathrm{q}(\mathrm{mg} / \mathrm{g})$ & 21.189 & 18.208 \\
\hline \multirow[t]{3}{*}{ Langmuir } & $\mathrm{b}(\mathrm{L} / \mathrm{mg})$ & 0.387 & 0.148 \\
\hline & $\mathrm{R}^{2}$ & 0.998 & 0.992 \\
\hline & $\mathrm{K}_{\mathrm{f}}(\mathrm{mg} / \mathrm{g})$ & 9.252 & 7.951 \\
\hline \multirow[t]{2}{*}{ Freundlich } & $\mathrm{n}$ & 0.142 & 0.738 \\
\hline & $\mathrm{R}^{2}$ & 0.805 & 0.615 \\
\hline
\end{tabular}

The Langmuir isotherm dominates the dyes adsorption process. This indicates that the adsorption only occurs on one active site. When the molecule occupies an active site, there will be no further absorption. If the active site of the adsorbent is saturated with adsorbate, the addition of adsorbate concentration does not increase the number of dyes adsorbed [27].

\section{CONCLUSION}

Ende natural zeolite can act as dye waste adsorbent by chemical activation treatment using $3 \mathrm{M} \mathrm{HCl}$. The adsorption capacity of natural zeolite absorbs methylene blue reaches $21.189 \mathrm{mg} / \mathrm{g}$, and methyl orange reaches $18.208 \mathrm{mg} / \mathrm{g}$. The optimum conditions for the absorption of methylene blue and methyl orange occurred at the adsorbent weight of $0.3 \mathrm{~g}$ and $0.4 \mathrm{~g}$. The contact time was 60 minutes and 90 minutes, and the optimum pH occurred at pH 6 and 2 . Weight factor adsorbent, contact time, and $\mathrm{pH}$ simultaneously influence both methylene blue and methyl orange absorption.

\section{ACKNOWLEDGMENTS}

The authors would like to thank the Flores Higher Education Foundation for funding this research through the Yapertif Grant 2020 and LPPM Flores University for providing support and opportunities so that this research can be carried out.

\section{REFERENCES}

[1] A. Riyardi, M. I. Hasmarini, Triyono, E.Setyowati, B.Setiaji, A. Wardhono, \& N.Wahab, "Deindustrialisasi pada industri tekstil dan produk tekstil di pulau Jawa", Journal of Economics and Policy, vol.6, no.1, pp.106119.2013

10.15294/jejak.v6i1.3752.

[2] I. Kahoul, N. Bougdah, F. Djazi, C.Djilani, P. Magri, \& M.S. Medjram, , "removal of methylene blue by adsorption onto activated carbons produced from agricultural wastes by microwave induced koh activation" chemistry and Chemical Technology, vol. 13.no.3, pp 365-371, 2018 10.23939/chcht13.03.365.

[3] S. M. Beldean-Galea, F.M. Copaciu, M.V. and Coman, "chromatographic analysis of textile dyes", Journal of AOAC International, 101(5), 13531370.

2018 10.5740/jaoacint.18-0066 .

[4] S. Lv, J. M. Liu, H. Ma, Z. Wang, C. Li, N. Zhao, \& S. Wang, " Simultaneous adsorption of methyl orange and methylene blue from aqueous solution 
using amino functionalized $\mathrm{Zr}$-based MOFs", Microporous and Mesoporous Materials, vol. 282, pp. 179-187,2019. 10.1016/j.micromeso.2019.03.017.

[5] Y. Liu, W. Zhu, K. Guan, C. Peng, \& J.Wu, 2018, Freeze-casting of alumina ultra-filtration membranes with good performance for anionic dye separation, Ceramics International, 44, 11901-11904.

10.1016/j.ceramint.2018.03.160.

[6] J. Zhang, S. Chen, Y. Zhang, X.Quan, H. Zhao, \& Y. Zhang, "Reduction of acute toxicity and genotoxicity of dye effluent using fenton-coagulation process", Journal Hazard Materials, vol. 274, pp. 198-204,2014. 10.1016/j.jhazmat.2014.04.022.

[7] P. A. Kaushik, \& Malik, ,"Process optimization for efficient dye removal by Aspergillus lentulus FJ172995", Journal Hazard Materials, vol. 185, pp. 837-843,2011

10.1016/j.jhazmat.2010.09.096.

[8] K. Hossainn, S. Quaik, N. Ismail, M. Raffatullah, M. Avasan, \& R. Shaik, , Bioremediation and detoxification of the textile wastewater with membrane bioreactor using the white-rot fungus and reuse of wastewater, Iran Journal Biotechnology. vol.14, no.3, pp.154162,2016

10.15171/ijb.1310 .

[9] J. Fu, Q. Xin, X. Wu, Z. Chen, Y. Yan, S. Liu ,M. Wang, \& Q. Xu, "Selective adsorption and separation of organic dyes from aqueous solution on polydopamine microspheres", Journal Colloid Interface Science, 461, 292304, 2016. 10.1016/j.jcis.2015.09.017.

[10] Y. D. Ngapa, "Study of the acid-base effect on zeolite activation and its characterization as adsorbent of methylene blue dye", Jurnal Kimia dan Pendidikan Kimia, vol.2,no.2, pp. 9096, 2017. 10.20961/jkpk.v2i2.11904.

[11] X. Lu, F. Wang, X. Li, K. Shih,\& E.Y. Zeng, "Adsorption and thermal stabilization of $\mathrm{Pb} 2+$ and $\mathrm{Cu} 2+$ by zeolite, Industrial and Engineering Chemistry Research, vol.55, no.32, pp. 8767-8773,2016.

10.1021/acs.iecr.6b00896.

[12] M.Gougazeh, , and J.C. Buhl, "Synthesis and characterization of zeolite $A$ by hydrothermal transformation of natural Jordanian kaolin", Journal of the Association of Arab Universities for Basic and Applied Science, vol.15, pp.35-42,2014 10.1016/j.jaubas.2013.03.007.

[13] Arryanto, Suwardi, Husaini, T. Affandi, S.Amini, M. Al-Jabri, P.Siagian, Setyorini, A. Rahman, \& Y.Pujiastuti, Zeolit dan masa depan bangsa, Imperium Pr, Yogyakarta, 2012. ISBN :602-98165-6-X.

[14] Y. D. Ngapa, S. Sugiarti, Z. and Abidin, , , Hydrothermal transformation of natural zeolite from Ende-NTT and its application as adsorbent of cationic dye, Indonesian Journal of Chemistry, Vol.16, no.2, pp. 138-143,2016 10.22146/ijc.21156".

[15] E. H. Mekatel, S.A mokrane, A. Aid, D. Nibou, \& M. Trari, "Photocatalytic reduction of $\mathrm{Cr}(\mathrm{VI})$ on nanosized $\mathrm{Fe} 2 \mathrm{O} 3$ supported on natural Algerian clay: Characteristics, kinetic and thermodynamic study", Comptes Rendus Chimie, vol.18, no.3, pp.336344, 2014.

10.1016/j.cej.2012.06.121.

[16] K. Kim, \& H. Ahn, "The effect of pore structure of zeolite on the adsorption of VOCs and their desorption properties by microwave heating", Microporous and Mesoporous Materials, vol.152, pp. 78-83,2011 doi:10.1016/j.micromeso.2011.11.051

[17] Y. Wang, H. Li, L.Gu, Q. Gan,Y. Li, \& G.Calzaferri,"Thermally stable luminescent lanthanide complexes in zeolite L", Microporous and Mesoporous Materials, vol.121, pp. 16,2009 . doi:10.1016/j.micromeso.2008.12.02

[18] N. Mansouri,\& N. Ikhtegar, "Porosity, characterization and structural properties of natural zeolite 
clinoptilolite as a sorbent", Environment Protection Engineering. vol.39, no.1, pp. 139-147, 2013. 10.5277/EPE1301118.

[19] S. E. Moradi \& A. Nasrollahpour, "Competitive adsorption and photodegradation of Methyl orange and Rhodamine $\mathrm{B}$ by $\mathrm{TiO} 2$ modified mesoporous carbon photo-catalyst on UV irradiation", Materials Technology, vol.32, no.12, pp. 716-723,2017. 10.1080/10667857.2017.1345837.

[20] M. A. B. Pauzan, M. H. Puteh, A. Yuzir, M. H. D. Othman, R. A. Wahab, \& M. Z. Abideen, "Optimizing ammonia removal from landfill leachate using natural and synthetic zeolite through statically designed experiment", Arabian Journal for Science and Engineering, vol.45, pp. 3657$3669,2019$.

10.1007/s13369-019-04204-y.

[21] S. Sivalingam, \& S. Sen, "Efficient removal of textile dye using nanosized fly ash derived zeolite-x: Kinetics and process optimization study", Journal of the Taiwan Institute of Chemical Engineers, vol.96, pp 305-314,2019. 10.1016/j.jtice.2018.10.032.

[22] Kustomo, \& S. J. Santoso, "Adsorption and kinetic studies of cationic (methylene blue) and anionic (methyl orange) dyes onto magnetite coated with humic acid", Jurnal Jejaring Matematika dan Sains, vol.1, no.2, pp. 64-69,2019.

10.36873/jjms.v1i2.212.
[23] X. Wang, D.Shao, G. Hou, \& X. Wang, ,Uptake of $\mathrm{Pb}(\mathrm{II})$ and $\mathrm{U}(\mathrm{VI})$ ions from aqueous solutions by the ZSM-5 zeolite", Journal of Molecular Liaquids, vol.207, pp.338-342,2015. 10.1016/j.molliq.2015.04.029.

[24] P. K. Pandey, S. K. Sharma, S. S. Sambi, "Removal of lead(II) from waste water on zeolite-NaX", Journal of Enviromental Chemichal Engineering, vol.3, no.4, pp. 26042610,2015,. 10.1016/j.jece.2015.09.008.

[25] W. E. Prasetyo, T. Kusumaningsih \& M. Firdaus, "Highly efficient and green synthesis of diacylphloroglucinol over treated natural zeolite mordenite and the optimization using response surface method (RSM), Synthetic Communication Journal,vol. 49, no.23, pp. 3352-3372,2019.

10.1080/00397911.2019.1666282.

[26] M. Auta, \& B. Hameed, , Chitosan-clay composite as highly effective and lowcost adsorbent for batch and fixed-bed adsorption of methylene blue, Chemichal Engineering Journal, vol. 237, no.1, pp.352-361,2014. 10.1016/j.cej.2013.09.066.

[27] M. Rasouli, N. Yaghobi, M. Hafezi, \& M. Rasouli, "Effect of nanocrystalline zeolite $\mathrm{Na}-\mathrm{Y}$ on meta-xylene separation", Journal of Industrial and Engeneering Chemistry, 18, 19701976,2012.

10.1016/j.micromeso.2011.11.045. 